\title{
Capsule Commentary on Bump et al., Hold-Over Admissions: Are They Educational for Residents?
}

\author{
Timothy W. Bodnar, MD \\ Department of Internal Medicine, Division of Metabolism, Endocrinology, and Diabetes, University of Michigan Health System, Ann Arbor, MI, \\ USA.
}

J Gen Intern Med 29(3):515

DOI: $10.1007 / \mathrm{s} 11606-013-2681-0$

(c) Society of General Internal Medicine 2013

$\mathrm{T}$ his study by Bump et al. ${ }^{1}$ surveyed internal medicine residents in a large academic residency about factors related to the work and educational value of "hold-over" admissions ("a resident receiving a patient already admitted by another resident"), estimated to comprise $43 \%$ of admissions. Residents report spending $30 \%$ less time on hold-overs compared to new admissions (56 $\mathrm{min}$ vs. $80 \mathrm{~min}$ ). They also report poorer understanding of the history and pre-admission course, and $26 \%$ feel "decreased ownership" of hold-over admissions. Despite the above, they perceive a neutral effect of the "hold-over" on the educational value of an admission.

Hold-overs are relatively new phenomena, first seen after the 2003 residency duty-hour restrictions (implementation of the 80-h work-week and 30-h shift), and now with much greater frequency, as the 2011 restrictions (limiting interns to 16-h shifts) resulted in widespread use of day/night shifts. Although this study was a single-center survey based on residents' recall, it is nonetheless an important look at the mechanics and perceptions of hold-overs.

The finding that resident perception of the educational value of an admission was not affected by hold-over status is notable, given concerns raised by internal medicine program directors in a survey in 2010 about the impending duty-hour restrictions. ${ }^{2}$ However, with significant reductions in time spent on a large portion of admissions, we should not assume educational non-inferiority. With the upcoming implementation of the Reporting Milestones, ${ }^{3}$ residency programs and teaching physicians will be charged with documenting readiness for independent practice in numerous domains. We've already seen our residents spend less time in direct patient care and more time on documentation and coordination of care, ${ }^{4}$ while having less availability for didactic activities. ${ }^{5}$ Even if the perception is that hold-over admissions provide similar educational benefit, we may very well see that key skills such a history-taking and physical examination suffer, while communication skills are more easily honed. The hold-over admission is here to stay. We will need to ensure that we maintain or improve the teaching and practice of all the skills necessary for completing an admission.

Conflict of Interest: The author was a chief medical resident during the 2011-2012 academic year, when the latest duty-hour restrictions went into effect. There are otherwise no disclosures related to any of the material in this article.

Corresponding Author: Timothy W. Bodnar, MD; Department of Internal Medicine, Division of Metabolism, Endocrinology, and Diabetes, University of Michigan Health System, Ann Arbor, MI, USA (e-mail: twbodnar@med.umich.edu).

\section{REFERENCES}

1. Bump GM, Zimmer SM, McNeil MA, Elnicki DM. Hold-over admissions: are they educational for residents? J Gen Intern Med. 2013. doi:10.1007/ s11606-013-2667-y.

2. Shea JA, Willett LL, Borman KR, Itani KM, McDonald FS, Call SA Chaudhry S, Adams M, Chacko KM, Volpp KG. Anticipated consequences of the 2011 duty-hours standards: views of internal medicine and surgery program directors. Acad Med. 2012;87:895-903.

3. Caverzagie KJ, Iobst WF, Aagaard EM, Hood S, Chick DA, Kane GC, Brigham TP, Swing SR, Meade LB, Bazari H, Bush RW, Kirk LM, Green ML, Hinchey KT, Smith CD. The internal medicine reporting milestones and the next accreditation system. Ann Intern Med. 2013;158:557-9.

4. Block L, Habicht R, Wu AW, Desai SV, Wang K, Novello Silva K, Niessen T, Oliver N, Feldman L. In the wake of the 2003 and 2011 duty-hours regulations, how do internal medicine interns spend their time? J Gen Intern Med. 2013;28:1042-7.

5. Desai SV, Feldman L, Brown L, Dezube R, Yeh H, Punjabi N, Afshar K, Grunwald M, Harrington C, Naik R, Confrancesco J. Effect of the 2011 vs. 2003 duty-hour regulation-compliant models on sleep duration, trainee education, and continuity of patient care among internal medicine house staff: a randomized trial. JAMA Intern Med. 2013;173:649-55. 